\title{
Extended Spectrem Beta Lactamases among Multi Drug Resistant Gram Negetive Bacilli Causing Urinry Tract Infection
}

\author{
${ }^{1}$ Ganga Sagar Bhattarai, ${ }^{2}$ Dipendra Shrestha, ${ }^{3}$ Bishnu Raj Tiwari \\ ${ }^{1}$ Privithi Narayan Campus, Tribhuvan University, Kaski, Nepal \\ ${ }^{2}$ National College, Tribhuvan University, Kathmandu, Nepal \\ ${ }^{3}$ School of Health and Allied Sciences, Pokhara University, Nepal
}

\begin{abstract}
Extended Spectrum Beta Lactamases (ESBL), the main cause of resistance to broad spectrum $\beta$-lactams, among uropathogenic bacteria have increased over time raising a global concern in the therapeutic management of infections caused by these organisms. The study was carried out in Janamaitri Hospital, Kathmandu between December 2012 to May 2013 with an objective to determine the status of ESBL producing Gram negative bacilli isolated from the urine sample, collected from patients suspected of urinary tract infection. Gram negative bacilli isolated were tested for the presence of ESBL by combined disk and antibiotic susceptibility by Kirby Bauer disc diffusion method following Clinical and Laboratory Standard Institute guidelines. Among the total 1105 mid-stream urine samples, 256 Gram negative bacilli were isolated. By screening test using third generation cephalosporins, 156 isolates were screened as ESBL producers and 91 isolates were positive for ESBL test by combined disk method. Among the 91 (35.55\%) ESBL producers, 70 (39.32\%) Escherichia coli, 16 (44.44\%) Klebsiella pneumoniae, and 5(33.33\%) Pseudomonas aeruginosa were found to be ESBL producers. Majority of ESBL producer showed resistance to ampicillin, co-trimoxazole, norfloxacin followed by ofloxacin. imipenem, amikacin and nitrofurantoin seemed to be the agent of choice for urinary tract infections when ESBL producers are susceptible to it. ESBL production found in these Gram negative bacilli with resultant microbial resistance to available cephalosporins and other agents may pose difficulties with the choice of therapeutic options for the treatment of severe infections.
\end{abstract}

Keywords: UTI, Extended Spectrum Beta Lactamases, Gram negative bacilli

Corresponding address: Ganga Sagar Bhattarai, Privithi Narayan Campus, Tribhuvan University, Kaski, Nepal. E-mail: hisagar17@yahoo.com

\section{INTRODUCTION}

Urinary tract infection is defined as a condition in which bacteria are established and multiply within the urinary tract. It is the leading cause of morbidity and health care expenditure in person of all the ages. ${ }^{1}$ The long range consequences of ignoring UTI can lead to kidney failure, septicemia, bacterial endocarditic, prostatitis and infertility. Worldwide, about 150 million people are diagnosed with UTI each year. ${ }^{2}$ More than $95 \%$ of urinary tract infections are caused by a single bacterial species. E. coli is the most frequent infecting organism in acute infection. ${ }^{3}$

Extended spectrum beta-lactamase (ESBL) organisms produce enzymes that hydrolyze the beta-lactam ring of beta lactam antibiotics like penicillins and cephalosporins, rendering them ineffective. Beta lactamase producers are typically gram negative organisms, namely E. coli, $K$. pneumoniae, $K$. oxytoca etc. ${ }^{4}$ The ESBL-producing organisms is the carbapenem family of antibiotics: imipenum, meropenum, and ertapenum.

The trend of the development of resistance by bacteria against antibiotics is too high with respect to the discovery of new antibiotic that we can sorrowfully assume a time is close to us when no antibiotic available will be effective against infectious bacteria. ${ }^{5}$ Developing countries are often unable to afford costly second line antibiotics to treat infections due to resistant organisms, resulting in prolonged illness with longer periods of infectivity and further spread of resistant isolates. These factors contribute to emergence of antibiotic resistance worldwide, however condition is even worst in developing countries. ${ }^{6}$ If an ESBL- producer is detected, it should always be reported as resistant to penicillins, cephalosporins and monobactams even if in vitro test results indicate susceptibility, since these may fail in treatment., ${ }^{7,8}$ The delay in detection and reporting ESBL-producer may lead to prolonged hospitalization of patients, increased morbidity and mortality as well as increased cost of health care $^{9}$ and hence can be considered an economic burden to society more in context of developing country like Nepal. Thus the detection of ESBL-producers aid physician in selection of antibiotics for patients use and also helps in the planning of strategies to control spread of ESBL-producers. This study was conducted with an objective to find out the presence of multidrug resistant ESBL-producing Gram negative strains to formulate effective antibiotic strategy to control infection and to prevent the spread of these strain.

\section{MATERIALS AND METHODS}

The study of Gram negative bacilli of UTI was conducted 
among patients suspected of UTI attending at Janamaitri Hospital, Kathmandu, Nepal. The period for this research work was from December 2012 to May 2013. During this research work, 1,105 midstream urine specimens were collected from patients clinically suspected of UTI and processed at laboratory of microbiology department. The history of all the patients including age, gender, symptoms were recorded in the data collection form from the requisition form obtained along with the mid stream urine for culture.

The patients attending at Janamaitri Hospital, Kathmandu, Nepal with clinical features of UTI were given a clean, dry sterile and leak proof container and requested for 5 to 10 $\mathrm{ml}$ midstream urine sample and examined. Semi quantitative culture technique was used to culture urine specimens and to detect the presence of significant bacteriuria by standard methods. Urine specimen was thoroughly mixed to ensure uniform suspension of bacteria before inoculating the agar plates. The inoculated MA and BA plates were aerobically incubated overnight at $37^{\circ} \mathrm{C}$. Identification and antimicrobial susceptibility testing of significant isolates was done by using microbiological techniques. ${ }^{7,10}$ The screen positive isolates i.e. suspected ESBL producers were subjected to Combined Disk (CD) test for confirmation of ESBL production using

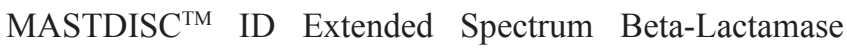
(ES $\beta L$ ) Detection Discs. All the data collected were analyzed using Statistical Software SPSS version 16.0, Descriptive analysis was done.

\section{RESULTS}

\section{Significant growth pattern among in and out Patients}

Out of 1105 samples, 369 samples received from the indoor patients, $82(22.22 \%)$ showed significant growth and out of the 736 samples received from the outdoor patients, 162 (22.01\%) showed significant growth, Among the MDR, $59.04 \%$ were from outpatients. Of the 163 isolates from outpatients $111(68.09 \%)$ were MDR among 93 isolates from inpatients 77 (82.79\%) were MDR (Table 1).

Table 1: Significant growth pattern among in and out Patients.

\begin{tabular}{|c|c|c|c|c|c|c|c|}
\hline \multirow[t]{2}{*}{ Source } & \multicolumn{2}{|c|}{ gnificant growth } & \multirow[t]{2}{*}{ MDR\% } & \multirow[t]{2}{*}{ Non MDR \% } & \multirow[t]{2}{*}{$\begin{array}{c}\text { No of } \\
\text { samples (\%) }\end{array}$} & \multirow{2}{*}{$\begin{array}{l}\text { Chi-Square } \\
\text { Value (95\% } \mathrm{Cl} \text { ) }\end{array}$} & \multirow[t]{2}{*}{ P-value } \\
\hline & Yes ( & Nol & & & & & \\
\hline Inpatients & $82(22.22)$ & 287 (77.71) & $77(82.79)$ & $16(17.20)$ & $369(33.3)$ & 0.24 to 0.35 & $<0.05$ \\
\hline Outpatients & $162(22.01)$ & $574(77.98)$ & 111 (68.09) & $52(31.90)$ & $736(66.6)$ & 0.25 to 0.33 & $<0.05$ \\
\hline Total & $244(22.08)$ & 861 (77.91) & 188 (73.43) & $68(26.56)$ & $1105(100)$ & 0.25 to 0.32 & $<0.05$ \\
\hline
\end{tabular}

Growth profile among different age group and gender.

Among the 244 significant growth, highest percent (51/244, $20.91 \%$.) of significant growth was obtained from age group 21-30. Among male patients the highest number of samples having significant growth was found in the age group of 41$50(8 / 21,38.10 \%)$. Among female the highest number of samples having significant growth was seen in age group of 61-70 with 30/85, 35.30\% ( Table 2 ).
Table 2: Gender Wise distribution of significant growth in various age groups.

\begin{tabular}{|c|c|c|c|c|c|c|}
\hline \multirow{2}{*}{$\begin{array}{l}\text { Age } \\
\text { group }\end{array}$} & \multirow{2}{*}{$\begin{array}{c}\text { Total } \\
\text { samples }\end{array}$} & \multicolumn{2}{|c|}{ Female } & \multicolumn{2}{|r|}{ Male } & \multirow{2}{*}{$\begin{array}{l}\text { Total significant } \\
\text { growth (\%) }\end{array}$} \\
\hline & & $\begin{array}{c}\text { No of } \\
\text { samples }\end{array}$ & $\begin{array}{l}\text { Significant } \\
\text { growth (\%) }\end{array}$ & $\begin{array}{c}\text { No of } \\
\text { samples }\end{array}$ & $\begin{array}{l}\text { Significant } \\
\text { growth (\%) }\end{array}$ & \\
\hline $0-10$ & 110 & 85 & $15(17.65)$ & 25 & $2(8.00)$ & $17(15.46)$ \\
\hline $11-20$ & 160 & 110 & $18(16.37)$ & 50 & $4(8.00)$ & 22 (13.75) \\
\hline $21-30$ & 215 & 170 & 45 (26.47) & 45 & $6(13.34)$ & $51(23.72)$ \\
\hline $31-40$ & 132 & 98 & $20(20.41)$ & 34 & $3(8.83)$ & $23(17.42)$ \\
\hline $41-50$ & 125 & 104 & $27(25.97)$ & 21 & $8(38.10)$ & $35(28.00)$ \\
\hline 51-60 & 122 & 94 & $21(22.34)$ & 28 & $6(21.43)$ & $27(22.14)$ \\
\hline $61-70$ & 112 & 85 & $30(35.30)$ & 27 & $4(14.82)$ & $34(30.35)$ \\
\hline $71-80$ & 99 & 68 & $20(29.42)$ & 31 & $9(29.04)$ & $29(29.29)$ \\
\hline $81-90$ & 30 & 14 & $3(21.43)$ & 16 & $3(18.75)$ & $6(20.00)$ \\
\hline Total & 1105 & 828 & $199(24.04)$ & 277 & 45 (16.25) & $244(22.08)$ \\
\hline
\end{tabular}

Distribution of bacterial isolates among male and female patients.

Among the 256 isolates, 205 (80.08) were isolated from female patients and among them154 (86.52) were E. coli (Table 3). significant polymicrobial growth (growth of two different microbes) was seen in 12 (4.49) specimens.

Pattern of suspected and conformed ESBL producing strains

Among the 188 Gram negative MDR, 156 were suspected ESBL-producers on primary screening, only 91 of them were confirmed as ESBL-producer after the confirmatory test. The 91 ESBL producing strains include $39.32 \%$ of $E$. coli, $44.44 \%$ of $K$. pneumoniae and $33.33 \%$ of $P$. aeruginosa (table 4).

Table 3: Distribution of bacterial isolates among male and female patients

\begin{tabular}{|c|c|c|c|c|c|}
\hline \multirow{2}{*}{ Organism isolated } & \multicolumn{2}{|c|}{ Female } & \multicolumn{2}{|c|}{ Male } & \multirow{2}{*}{ No of isolates (\%) } \\
\hline & Total No & $\%$ & Total No & $\%$ & \\
\hline Escherichia coli & 154 & 86.52 & 24 & 13.48 & $178(69.53)$ \\
\hline Klebsiella pneumonia & 26 & 72.23 & 10 & 27.77 & $36(14.06)$ \\
\hline Pseudomonas aeruginosa & 8 & 853.34 & 7 & 46.67 & $15(5.85)$ \\
\hline Proteus vulgaris & 4 & 57.15 & 3 & 42.86 & $7(2.73)$ \\
\hline Morgenella morganii & 4 & 66.67 & 2 & 33.33 & $6(2.34)$ \\
\hline Proteus mirabilis & 3 & 60.00 & 2 & 40.00 & $5(1.95)$ \\
\hline Citrobacter spp. & 2 & 50.00 & 1 & 50.00 & $3(1.17)$ \\
\hline Enterobacter spp. & 2 & 100.00 & 0 & 0.00 & $2(0.78)$ \\
\hline Klebsiella oxytoca & 2 & 50.00 & 2 & 50.00 & $4(1.56)$ \\
\hline Total & 205 & 80.08 & 51 & 19.92 & $256(100)$ \\
\hline
\end{tabular}

Table 4: Pattern of suspected and conformed ESBL producing strains.

\begin{tabular}{|l|c|c|c|c|c|}
\hline \multicolumn{1}{|c|}{ Organism isolated } & $\begin{array}{c}\text { No of } \\
\text { isolate }\end{array}$ & $\begin{array}{c}\text { MDR } \\
\text { isolates }\end{array}$ & $\begin{array}{c}\text { Suspected } \\
\text { ESBL }\end{array}$ & $\begin{array}{c}\text { ESBL } \\
\text { producer No. }\end{array}$ & $\begin{array}{c}\text { \% of total } \\
\text { isolates }\end{array}$ \\
\hline Escherichia coli & 178 & 138 & 115 & 70 & 39.32 \\
\hline Klebsiella pneumoniae & 36 & 25 & 23 & 16 & 44.44 \\
\hline Pseudomonas aeruginosa & 15 & 10 & 10 & 5 & 33.33 \\
\hline Morganella morganii & 6 & 3 & 2 & 0 & 0.00 \\
\hline Proteus vulgaris & 7 & 4 & 1 & 0 & 0.00 \\
\hline Proteus mirabilis & 5 & 3 & 2 & 0 & 0.00 \\
\hline Klebsiella oxytoca & 4 & 2 & 2 & 0 & 0.00 \\
\hline Citrobacter spp. & 3 & 2 & 0 & 0 & 0.00 \\
\hline Enterobactor spp. & 2 & 1 & 1 & 0 & 100 \\
\hline \multicolumn{1}{|c|}{ Total } & 256 & 188 & 156 & 91 & 35.55 \\
\hline
\end{tabular}




\section{DISCUSSION}

Out of 1105 specimens, significant growth was obtained only from $22.08 \%$ samples. Out of total patients, 828 (74.94\%) of the patients were female and $277(25.06 \%)$ were male and the association was statistically significant $(\mathrm{p}<0.05)$.

Among the 244 significant growth, highest percent (51/244, $20.91 \%$.) of significant growth was obtained from age group 21-30. Among male patients the highest number of samples having significant growth was found in the age group of 41$50(8 / 21,38.10 \%)$. among female the highest number of samples having significant growth was seen in age group of $61-70$ with $(30 / 85,35.30 \%)$. This growth pattern showed that urinary tract infection is increasing with age. The prevalence of urinary tract infection increase with age which is seen in both sexes. ${ }^{11}$ High prevalence of UTI in old age male may be like prostatitis, diabetes and weak immune status. Although the majority of cases (76\%) spontaneously resolve, infections with urea splitting bacteria (such as Proteus) are more likely to have significant squeal, including stone formation and permanent renal damage.

The study reveal that the gram negative bacteria i.e, E. coli $(69.53 \%)$ was found to be the most common one followed by Klebsiella species (14.06\%), Pseudomonas aeruginosa (5.85\%). Proteus species (2.73\%), Morganella morganii (2.34\%), Citrobacter species and (1.17\%), Enterobacter species $(0.78 \%)$. E. coli have special virulent properties contributing to their being a major uro-pathogen throughout the world.

Out of the total Gram negetive isolates, $73.43 \%$ isolates are multidrug resistant. In this study, highest number of MDR (77.52\%), was found in E. coli, followed by Klebsiella pneumoniae (66,66\%) Citrobacter spp. (66.66\% \%), Morganella morganii (57.14\%), Psudomonas aeruginosa $(50.00 \%)$ Klebsiella oxytoca $(50.00 \%)$ and Enterobacter spp $(50.00 \%)$. The high degree of resistance could be explained by the fact that drugs are easily available without doctor's prescription from pharmacy and in developing countries like Nepal self-medication is a common practice and this might probably be a major cause of antibiotic resistance in clinical isolates. patient only think of going to the hospitals when they are unable to treat themselves. Expired antibiotics, self-medication counterfeit drugs, inadequate hospital control measures can as well promote the development of resistance in clinical isolates. ${ }^{12}$ These results resembled the outcomes of previous studies done by Baral and Thakur. ${ }^{12,13}$ The emergence of MDR is clearly related to the quantity of antibiotics and how they are being used. ${ }^{14}$ Antimicrobial patterns are continually evolving and multidrug resistance among some of the most important human pathogens is increasing. Therefore, surveillance systems will need to be continued to ensure the provision of the safe and effective emprical therapies. Among the Gram negative multidrug resistant bacteria screened for ESBL production, majority
(82.97\%) were found possible ESBL producers. In this study $44.44 \%$ of Klebsiella pneumoniae and none of Klebsiella oxytoca were ESBL producer. There is considerable geographical difference in the occurrence of ESBLs. Among countries, territories, within countries, hospital-to-hospital variability in occurrence may also be marked. ${ }^{15}$

In the present study out of 188 gram negative bacteria 91 $(35.55 \%)$ were ESBL producers. The prevalence of ESBL producing Gram negative pathogen varies greatly from country to country and among the hospitals within the country. Similar prevalence rates of ESBL in Nepal were reported by the findings of Manandhar. ${ }^{16}$ NCCLS detection methods are based on a phenotypic profile that has potential to yield false positive and false negative results. In some of the isolates, additional mechanisms of resistance, such as AmpC- beta lactamases, porin changes and inhibitor resistant TEMs (IRTs) and SHV beta-lactamases with reduced affinities for beta-lactamase inhibitors can mask CA inhibition. In addition hyperproduction of Class A ' $\mathrm{K} 1$ ' chromosomal protease by $\mathrm{Kl}$. oxytoca can give positive clavulanate synergy test with cefotaxime and cefepime (never ceftazidime), so the producers are confused with ESBL producers. The high prevalence of ESBL-producing isolates described in this study was probably due to the long term hospital stay with large amount of $3^{\text {rd }}$ generation cephalosporins consumed. The sensitivity of DDST varies with the distance between the discs ${ }^{17,18}$ reported that the clinical strains producing SHV$6 \mathrm{ESBL}$ and AmpC type $\beta$-lactamase producers would not be detected by double disc diffusion tests. In the presence of AmpC along with ESBL in Gram negative organisms, the DDST may not show positivity as AmpC type beta lactamase inhibits the action of clavulanate and hence obscures the synergistic effect of clavulanic acid and $3^{\text {rd }}$ generation cephalosporins.

In the present study, $49.00 \%$ of strains showed resistance to ofloxacin (p-value $<0.05$ ), $63.67 \%$ to co-trimoxazole and $23.4 \%$ to nitrofurantoin. The high level of drug resistance seen among $E$. coli is mediated by beta-lactamases, which hydrolyze the beta-lactam ring inactivating the antibiotic, the classical TEM-1, TEM-2, and SHV-1 enzymes are the predominant plasmid-mediated beta-lactamases of Gam negative rods. ${ }^{19}$ Mutations at the target site i.e. gyr A, which is a gyrase subunit gene, and $\operatorname{par} \mathrm{C}$, which encodes a topoisomerase subunit, confer resistance to fluoroquinolones. ${ }^{20}$

For ESBL producing Enterobacteriaceae, imipenem was found to be effective against all the isolates indicating that they are the drugs of choice for treating serious infections caused by ESBL-producing microorganisms but this can only be used, if there were no alternative second line drugs of choice. ${ }^{21}$ However the other carbapenem agent, meropenem was not found to be as effective as imipenem. Also the data indicate that a valuable option for treatment is represented 
by amikacin, a bactericidal drug effective against ESBL producing strains.

\section{CONCLUSION}

The trend of microbial resistant in our contest is remarkably high which impairs the efficacy of antimicrobial agents and results in substantial increase in death rate and healthcare cost. ESBL producing bacteria are typically associated with MDR bacteria. Hence, for updated knowledge of antimicrobial susceptibility pattern of bacterial strain, for the proper selection and use of antimicrobial drugs and for development of an appropriate prescribing policy, the MDR and ESBL producing bacteria should be isolated and identified in bacteriological laboratory.

\section{ACKNOWLEDGEMENTS}

We would like to thanks Janmaitri hospital, Kathmandu Nepal for providing laboratory facilities to conduct the research.

\section{REFERENCES}

1. Tuladhar NR, Banjade N, Pokhrel BM, Rizal B, Manandhar R, Shrestha S, Shah A and Chaurasia S. Antimicrobial resistant bacterial strains from inpatients of Tribhuvan University teaching hospital Kathmandu. J. Inst Med, 2003; 25:19-26.

2. Alo MN, Saidu AY, Ugah UI, Alhassan M. Prevalence and Antbiogram of Bacterial Isolates Causing Urinary Tract Infections at Federal Teaching Hospital Abakaliki I (FETHA I). British Microbiol. Res. J, 2015; 8(2):403-17.

3. Forbes BA, Sahm DF and Weissfeld AS. Bailey and Scott's Diagnostic Microbiology.11th edn. Mosby, Inc USA, 2002.

4. Akram M, Shahid M and Khan AU. Etiology and antibiotic resistance patterns of community-acquired urinary tract infections in JNMC Hospital Aligarh, India. Ann. Clin. Microbiol. Antimicrob, 2007; 6: 4-6.

5. Levi SB. Antibiotics Resistance: Consequences of inaction. Clin. Infect. Dis, 33 (Suppl 3): 2001; S124-129

6. WHO). Basic laboratory procedures in clinical bacteriology. 2nd edition World Health Organization, Geneva, 2004.

7. Clinical and Laboratory Standards Institute (CLSI). Performance Standards for Antimicrobial Susceptibility Testing; seventeenth informational supplement. Clin. and Lab. St. Inst, 27: 2007; M100-S17.

8. Paterson DL and Bonomo RA. Extended Spectrum Beta Lactamases: A Clinical Update. Clin. Microbiol Rev, 2008;18:657-86.

9. Lautenbach E, Patel JB, Biker WB, Edelstein PH and Fishman NO. Extended spectrum beta lactamase producing E. coli and Kl. pneumoniae. Risk factors for infection and impact of resistance on outcomes. Clin. Infect. Dis, 2001; 32:1162-71.

10. Cheesbrough M. District laboratory Practice in tropical Countries Part 2 Cambridge University Press, 2000; pp. 9-115.

11. Smith A and Almond M. Management of urinary tract infection in the elderly, Trends in Urol. Gynaecol. and Sex. Health, 2007; 5:125-131

12. Thakur S, Pokhrel N and Sharma M. Prevalence of Multidrug Resistant Enterobacteriaceae and Extended Spectrum $\beta$ Lactamase Producing E. Coli in Urinary Tract Infection. Res. J. Pharm, Bio and Chem. Sci,2013; 4(2):1615.

13. Baral P, Neupane S, Marasini BP, Ghimire KR, Lekhak B, Shrestha B. High prevalence of multidrug resistance in bacterial uropathogens from Kathmandu, Nepal. BMC Research notes, 2012 Jan 19;5(1):1.

14. Levy SB, Marshall B. Antibacterial resistance worldwide: causes, challenges and responses. Nature medicine, 2004 Dec $1 ; 10:$ S122-9.

15. Babini GS and Livermore DM. Antimicrobial resistance amogs Klebsiella spp. Collected from intensive care units in Southern and Western Europe in 1997-1998. J.Antimicrobio. Chemother, 2000; 45:183-189

16. Manandhar T, Koirala J, Pokhrel BM and Ghimire P. Status of Extended spectrum beta lactamase producing E. coli and Klebsiella spp. in Urinary tract infection. J. Inst. Med, 2006; 28(2):24-29.

17. Ho PL, Tsang DN, Que TL, Ho M and Yuenky. Comparison of screening methods for detection of Extended Spectrum $\beta$-Lactamases and their prevalence among E. coli and Klebsiella spp. in Hong kong. APMIS, 2000; 108:237-240

18. Zali FN, Chanawaong A, Kerr KG, Birkenhead D and Hawkey PM. Detection of extended-spectrum beta-lactamases in members of the family enterobacteriaceae: comparison of the MAST DD test, the double disc and the Etest ESBL. J Antimicrob Chemother, 2000 Jun; 45(6):881-5.

19. Livermore DM. $\beta$-lactamases in laboratory and clinical resistance. Clin. microbial rev, 1995; 8:557-584.

20. Ozeki S, Deguchi T, Yasuda M, Nakano M, Kawamura T, Nishino Y and Kawada Y. Development of a rapid assay for detecting gyrA mutations in E.coli and determination of incidence of gyrA mutations in clinical strains isolated from patients with complicated urinary tract infections. J. Clin. Microbiol, 1997; 35:2315-2319.

21. Denyer SP, Hodges NA and Gorman SP. Hugo and Russell's Pharmaceutical Microbiology. 7th edition. Blackwell Scientific Publications, UK, 2004. 